\title{
EDUCAÇÃO NO ATUAL CENÁRIO POLÍTICO E ECONÔMICO
}

Esta edição foi produzida no contexto das mobilizações e dos debates contemporâneos acerca dos rumos para o país. Após a eleição presidencial ocorrida no final de 2014, disputas se acirraram no cenário nacional e grandes temas, muitos deles caros para o campo educacional, ganharam a cena da mídia brasileira.

Um desses temas está relacionado à redução da maioridade penal. A Comissão de Constituição e Justiça e de Cidadania da Câmara dos Deputados, aprovou no último dia 31 de março a admissibilidade da PEC 171/93 que reduz a maioridade penal de 18 para 16 anos. Essa aprovação implica em que se assumiu ser essa uma possibilidade de revisão constitucional que agora segue para análise de uma comissão especial da Câmara que examinará seu conteúdo e que, se receber $3 / 5$ de votos favoráveis entre os deputados, tramitará no senado federal. Sob o argumento amplamente divulgado pela grande mídia, muitos tem defendido essa como a alternativa para a redução da violência social. Entretanto, dados apontam que, em países que adotaram tal medida, não se registrou redução nos índices de violência, aliás, Alemanha e Espanha voltaram atrás na decisão de criminalizar menores de 18 anos de idade. Atualmente, $70 \%$ dos países adotam os 18 como maioridade penal. Além disso, dados do Unicef divulgados recentemente, apontam que apenas $1 \%$ dos homicídios ocorridos no Brasil, são cometidos por jovens entre 15 e 17 anos. Num contexto de ampliação do pensamento conservador, esses dados são desprezados e assume-se a redução da maioridade como forma de reverter o quadro de violência no país.

A ortodoxia da política econômica para enfrentamento da crise internacional e do consequente crescimento das contas da dívida pública e da inflação produzem impactos diretos na oferta de serviços públicos e na seguridade social. No campo da seguridade social as medidas já afetaram o seguro-desemprego, o abono salarial, as pensões, entre outros benefícios. No setor educacional, as medidas de contingenciamento e de cortes no orçamento, adotadas em todas as esferas de governo, já estão produzindo efeitos diretos nas negociações salariais em diversos estados e municípios, com destaque para a greve dos professores do Estado do Paraná e, agora, no Estado de São Paulo. As greves e mobilizações, que se expandem para outras unidades da federação, tem como pauta comum a luta pela valorização dos profissionais da educação e a melhoria das condições de trabalho.

No embalo das medidas de corte na seguridade social, no dia 08 de Abril de 2015 (quarta-feira) a Câmara dos Deputados aprovou o texto-base do Projeto de Lei 4330/04 que regulamenta os contratos de terceirização no setor privado e no setor público, nesse último

\begin{tabular}{l|l|l|l|l|l|l} 
(C) ETD - Educ. Temat. Digit. & Campinas, SP & v.17 & n.1 & p.1-5 & jan./abr.2015 & ISSN 1676-2592
\end{tabular}


para empresas de economia mista, subsidiárias e controladas pela União, Estados e Municípios. Essa lei aguarda a manifestação do poder executivo para sua aprovação. O projeto poderá ampliar o número de trabalhadores terceirizados no país da casa dos 12 milhões para 30 milhões, dentro de uma massa total de 50 milhões de trabalhadores com registro formal, ou seja, com carteira assinada, descontando-se os trabalhadores do setor público. O projeto vem se somar ao programa de reformas trabalhistas iniciada na década de 1990 para desmonte do conjunto de direitos de proteção ao trabalhador. A medida tende a afetar o setor público pela queda da arrecadação, uma vez que empresas menores recolhem menos impostos. Ainda no que concerne ao setor público, vale destacar que essa medida poderá servir de base para maior desregulamentação do trabalho nesse setor que já vem sendo bastante afetado pela terceirização.

No início do mês de abril assumiu o Ministério da Educação o filósofo Renato Renato Janine Ribeiro. O novo ministro terá pela frente dois desafios fundamentais: o primeiro e mais imediato será o de enfrentar aqueles impostos pela equipe econômica do governo concernentes aos cortes orçamentários; o segundo grande desafio, que se relaciona ao primeiro, será o de fazer valer as metas do novo PNE (2014-2024). Vale destacar, em razão desse quadro, como o novo ministro irá fazer valer o plano de governo da presidente Dilma para expansão da rede federal de ensino tecnológico e das universidades públicas, realizar concursos e prover infraestrutura. $\mathrm{O}$ que se espera ainda é saber como o novo ministro irá lidar com as forças do mercado, fundamentalmente das IES privadas, fortalecidas, nesses últimos anos, com os aportes de recursos públicos via Fies e o ProUni. Há também muitas expectativas em torno do relacionamento que o novo ministro irá estabelecer com o setor empresarial organizado em torno do movimento "Todos pela Educação". Vale destacar que essa entidade vem influindo, desde a gestão Lula, em muitas das decisões de política educacional em vários dos seus aspectos, mas fundamentalmente no que se referem à avaliação dessas políticas atreladas a esquemas de responsabilização.

No sentido de contribuir para pautar a agenda político-educativa no cenário antes descrito, o número da Revista Educação Temática Digital (ETD) que agora apresentamos para o leitor traz uma coletânea de artigos instigantes. Esperamos que provoquem o avanço do debate acadêmico e político sobre a educação brasileira e os desafios que se apresentam no contexto atual. Os artigos que compõem essa Revista, estão organizados no que estamos nomeando, dois grande blocos temáticos: política educacional e cultura e temas contemporâneos.

No primeiro bloco, encontra-se o artigo "Políticas nacionais ambientais e de ação afirmativa: gestão no ambiente de uma instituição de educação profissional" que trata das atribuições e demandas colocadas pela lei 11 892/2008 que introduziu Rede Federal de Educação Profissional, Científica e Tecnológica e criou os Institutos Federais de Educação, Ciência e Tecnologia (IFTs). Ao mesmo tempo, propõe mudanças para essa formação e expressa interesse em questões sociais e ambientais. Em seu estudo o autor analisa o processo de expansão ocorrido no IFTSP e os desafios ao cumprimento dos objetivos da política de \begin{tabular}{l|l|l|l|l|l|l}
\hline (C) ETD-Educ. Temat. Digit. & Campinas, SP & v.17 & n.1 & p.1-5 & jan./abr.2015 & ISSN 1676-2592
\end{tabular} 
expansão nos aspectos referentes às questões de políticas ambientais e de ações afirmativas na instituição. O texto apresenta dados de pesquisa, efetuada junto ao quadro de servidores e de docentes, que retrata como essas políticas foram concretizadas em práticas no âmbito da gestão e do currículo na instituição.

O artigo "A perspectiva epistemológica em Antonio Gramsci e a pesquisa de políticas educacionais" apresenta uma análise dos desafios da pesquisa educacional a partir da perspectiva gramsciana e seus vínculos com a filosofia da práxis marxista. Revisitando os principais conceitos do pensador italiano, o autor questiona a neutralidade axiológica na produção do conhecimento para situá-la como elemento que pode influir no campo da cultura tanto para subsidiar a elaboração de políticas o questioná-las. O destaque do texto fica por conta do debate em torno do papel dos intelectuais orgânicos, do conhecimento por ele produzido no campo das políticas educacionais numa sociedade de classes marcada por conflitos de interesse.

A partir de uma análise dos microdados do Censo Escolar e do Censo Demográfico de 2010, o do artigo "Qualidade e equidade das condições de oferta no ensino fundamental" analisa as condições de oferta educacional no município de Ribeirão Preto, em São Paulo. Trabalhando com o conceito de equidade, o autor analisou as relações entre as condições socioeconômicas da população com as condições das instituições de ensino fundamental do município. Os dados revelam que os equipamentos com maiores problemas, no que concerne a infraestrutura, estão situados nas regiões mais pobres do município.

O artigo "Accountability em educação:mais regulação da qualidade ou apenas um estágio do estado-avaliador?" apresenta uma análise crítica dos atuais esquemas avaliativos no campo das políticas públicas em educação, fundamentalmente pela ancoragem dessas práticas na responsabilização dos profissionais da educação. $\mathrm{O}$ autor analisa o processo global que vem induzindo essas práticas, ao mesmo tempo em que questiona a entrada desses procedimentos, típicos do Estado-avaliador, no Brasil.

O texto "Relação Estado e sociedade civil nas políticas educacionais para a educação de jovens e adultos" que nos apresenta uma análise dos debates em torno da relação entre Estado e sociedade civil em torno da implementação e acompanhamento e o financiamento das políticas de Educação de Jovens e Adultos - EJA no Brasil. O texto pontua as implicações referentes ao fortalecimento dessa modalidade da educação básica com a introdução das parcerias público-privado e da maior participação das organizações não-governamentais, num contexto de "diminuição da responsabilidade do Estado", conforme destaca o autor.

Fechando esse bloco, o artigo "Políticas públicas em educação na Guiné-Bissau" nos apresenta uma análise das estruturas educacionais deixadas pelo colonialismo português na Guiné-Bissau., enfocando o papel desempenhado pela Igreja Católica sua relação com o Estado português na implantação da missão civilizatória sobrepondo uma cultura oral pela 
cultura escrita europeia. O autor aborda os aspectos históricos constitutivos da educação e a reprodução das desigualdades no atual sistema de ensino desse país.

Num segundo grande bloco temático, estão dois artigos que, partem de uma perspectiva teórica pós-estruturalista, especialmente pautados pelos trabalhos de Deleuze e Guattari. O primeiro deles, intitulado "Guattari e a topografia da máquina escolar" pauta-se por "pensar a topografia da máquina escolar" com o intuito de "ativar rupturas e atopias" acerca da experiência escolar e educativa. Nesse sentido, o artigo dialoga com o intitulado "Implicações midiáticas e acadêmicas nos modos de apropriação do pensamento de Gilles Deleuze e Félix Guattari para o debate em educação no Brasil”, que busca compreender formas de difusão no país e apropriação do pensamento dos dois autores, especialmente no campo educacional. Esse último provoca os pesquisadores da área, especialmente, ao afirmar que é a penetração desse referencial nos trabalhos educacionais que produziu "uma guinada para o pensamento da diferença" e permitiu que se escapasse da "relativa estagnação na qual supostamente se encontravam as pesquisas da área".

No sentido de revisão acerca da pesquisa no campo educacional, o artigo intitulado "Pesquisa em Educação: investigação sobre a ação pedagógica" apresenta uma discussão teórica sobre a temática partindo de trabalhos clássicos sobre metodologia de pesquisa. Contribuindo com o debate sobre a pesquisa em ciências sociais, com suas interfaces na educação, o artigo "Participatory Photography: Language Minority Teenagers' Sense of Belonging?" provoca uma importante reflexão sobre possibilidades de termos crianças e adolescentes como co-produtores de pesquisa através, em especial, da captura de imagens com a câmera fotográfica.

Corroborando com a atualidade do número aqui apresentado, encontram-se dois artigos que abordam outras temáticas extremamente relevantes: os artigos "Ideologia e reconhecimento: reflexões sobre a obrigatoriedade da temática história e cultura afrobrasileira" e "A ONU, suas normativas e o ordenamento jurídico para o atendimento de adolescentes em conflito com a lei no Brasil: as políticas de socieducação”. Esses são textos importantes para pesquisadores que estão interessados no debate de temáticas relevantes para as ciências sociais na sua articulação com as questões educacionais e com o trabalho escolar. Da mesma forma, o artigo intitulado "A formação de professores alfabetizadores e o programa Ler e Escrever" traz contribuição destacável para os pesquisadores interessados na formação de professores, partindo de estudo com professoras alfabetizadoras da cidade de Campinas (SP) que participam do Programa Ler e Escrever, é possível compreendermos parte do processo complexo que perpassa tal formação.

Contribuindo para uma análise ampliada sobre o quadro educacional brasileiro e em diálogo com os artigos anteriormente apresentados, publicamos neste número uma notícia do ano de 1931 em que é possível constatar a difícil tarefa que a educação brasileira enfrenta há anos no sentido de universalizar a escola e constituir um sistema nacional de ensino. 
Assim, diante dessa diversidade de textos e de temáticas atuais e primordiais para o campo educacional, convidamos todos à leitura com a expectativa de que encontrem elementos para subsidiar seus estudos.

Boa leitura!

Dirce Djanira Pacheco e Zan ${ }^{1}$

Evaldo Piolli ${ }^{1}$

Abril/2015.

Como citar este documento:

ZAN, Dirce Djanira Pacheco e; PIOLLI, Evaldo. Editorial: "Educação no atual cenário político e econômico". ETD - Educ. Temat. Digit., Campinas, SP, v.17, n.1, p.1-5, jan./abr. 2015. Disponível em: 〈https://www.fe.unicamp.br/revistas/ged/etd/article/view/7093〉 Acesso em: 30 abr. 2015.

\footnotetext{
${ }^{1}$ Docentes da Faculdade de Educação/UNICAMP; Membros do Comitê Editorial da ETD.
} 